\title{
Deep Impact? How Journalists Perceive the Influence of Public Relations on Their News Coverage and Which Variables Determine This Impact
}

Communication Research 2018, Vol. 45(7) 1031-1053

(C) The Author(s) 2015

Article reuse guidelines: sagepub.com/journals-permissions DOI: I0.1।77/00936502।56I7505 journals.sagepub.com/home/crx

@SAGE

\section{Magdalena Obermaier', Thomas Koch², and Claudia Riesmeyer'}

\begin{abstract}
Journalists perceive $25 \%$ to $80 \%$ of their coverage to be influenced by public relations (PR). However, there is hardly any research on what factors determine where on this wide spectrum an individual journalist will fall. This study analyzed the extent and source of the perceived influence of PR on news coverage via a quantitative survey of German journalists. On average, participants perceived over one third of their work to be influenced by PR, and a number of variables were found to be associated with the degree of this impact. Role conceptions as populist mobilizers and newsroom conventions discouraging excessive reliance on PR decreased the influence of PR on news coverage. Secondary employments in the field of $P R$, having close personal relationships with PR professionals, and considering interests of publishers or advertisers increased the impact of PR on journalistic content.
\end{abstract}

\section{Keywords}

journalists, public relations, perceived influence, news coverage, quantitative survey

\footnotetext{
'Ludwig-Maximilians-University of Munich, Germany

2Johannes Gutenberg-University of Mainz, Germany

Corresponding Author:

Magdalena Obermaier, Ludwig-Maximilians-University of Munich, Oettingenstraße 67,

80538 Munich, Germany.

Email: obermaier@ifkw.Imu.de
} 
Dealing with public relations (PR) is often a balancing act for journalists. On the one hand, journalists depend on PR, especially when working with limited time and financial resources (Curtin, 1999; Gandy, 1982). On the other hand, relying too much on PR can lead to less rigorous investigations and a loss of journalistic independence: While journalists have a duty to inform the public, PR professionals are hired to serve the particular interests of their clients (Lewis, Williams, \& Franklin, 2008; Reich, 2010; Riesmeyer, 2007). In light of this conflict of interests, journalists often depict PR and PR professionals as a necessary evil (Aronoff, 1975; Cameron, Sallot, \& Curtin, 1997).

Despite this critical attitude toward PR sources, research shows that $25 \%$ to $80 \%$ of journalistic coverage is influenced by PR (Cameron et al., 1997). Because these estimations vary a great deal, it might be reasonably assumed that a number of variables determine the degree of influence PR have on journalistic content. Research to date has primarily aimed at quantifying the impact of PR on journalistic content by analyzing the "proportion of news items originating from press releases, press conferences or individual contacts between sources and reporters" (Donsbach, 2004, p. 136). Other studies have described different aspects of the relationships between journalists and PR professionals, such as forms of contact, instruments of power, or personal relations (Cho, 2006; Curtin, 1999; Jo \& Kim, 2004; Pincus, Rimmer, Rayfield, \& Cropp, 1993; Shin \& Cameron, 2003; Waters, Tindall, \& Morton, 2010). However, these studies have not analyzed how these factors determine the influence of PR on news coverage. Therefore, "it remains unclear what factors in the news process have finally brought about a certain "impact"' (Donsbach, 2004, p. 136). Hence, the purpose of the present study is both to identify the determinants of the perceived influence of PR on journalistic content and to analyze these determinants' relative impact (also see Reich, 2010; Sinaga \& Wu, 2007).

\section{Influences and Perceived Influences on Journalistic Content}

A number of theoretical frameworks pertain to possible influences on journalistic news coverage (Ettema, Whitney, \& Wackman, 1987; Preston, 2009; Whitney, Sumpter, \& McQuail, 2004). One of the most prominent frameworks is the levels-ofinfluence approach (Shoemaker \& Reese, 1996), which proposes five main groups of variables that influence journalistic content: attributes of the individual journalists, media routines, and attributes of media organizations, as well as extra-media and ideological influences. More recently, Preston (2009) has instead differentiated individual influences, media routines, organizational influences, political-economic factors, and cultural and ideological power. Although both models name similar variables of influence, these variables are placed on different levels (Hanitzsch et al., 2010).

Both conceptualizations propose that individual attributes such as journalist demographics and role conceptualizations can affect journalistic content. For instance, journalists who see themselves as adversaries to societal elites may value different topics and portray information differently than journalists who aim to neutrally and quickly disseminate information (Meyen \& Riesmeyer, 2012; Preston, 2009; Shoemaker \& Reese, 1996; Weaver \& Wilhoit, 1991, 1996; Weaver \& Willnat, 2012; Weischenberg, Malik, \& Scholl, 2006). However, such individual attributes were shown to only 
modestly affect journalistic content, when compared with the impact of journalistic routines and organizational attributes (Esser, 1998; Preston, 2009).

Journalistic routines, however, defined as "routinized, repeated practices and forms that media workers use to do their jobs" (Shoemaker \& Reese, 1996, p. 105), can strongly affect news coverage. Journalists are increasingly constrained by shortages of time and financial resources in their daily work routines, making them more likely to rely on easily available sources such as online information or PR when producing journalistic content (Klinenberg, 2005; Preston, 2009). Organizational attributes (e.g., conventions in the newsroom and economic pressures) also influence news coverage. With regard to newsroom conventions, journalists may, for example, follow their publishers' policies or serve the interests of advertisers by coordinating their journalistic content correspondingly (Breed, 1955; Hanusch, Hanitzsch, \& Lauerer, 2015; Klinenberg, 2005; Sigelman, 1973); however, the influence of these factors may vary among different media systems (Preston, 2009). Economic pressures, such as the degree of competition a media organization faces or its financial situation, can also affect news coverage (Shoemaker \& Reese, 1996).

On a media systems or ideological level, factors such as media laws or freedom of the press can determine journalistic work (Hanitzsch et al., 2010). Because we are interested in the influences on journalistic content in a single country, media systems and ideological levels play a negligible role in the present study, as the German media is generally free of such rules or constraints.

The factors given for both individual attributes and journalistic routines mainly refer to objective influences, although journalists' perceived influences can also strongly affect journalistic content. The importance to consider perceived influences was clearly shown by Hanitzsch et al. (2010), who demonstrated in a cross-national study that journalists perceive procedural (e.g., time pressure), professional (e.g., conventions in the editorial department), and organizational influences (e.g., the work routines of publishers) to be the most important determinants of their work. Participants in Hanitzsch et al.'s study also reported economic factors (e.g., anticipated interests of advertisers) as influencing their news coverage (Hanitzsch et al., 2010; also see Hanitzsch \& Mellado, 2011).

The literature reviewed in this section strongly indicates that journalistic routines and organizational characteristics can markedly affect journalistic content; in addition, albeit weaker, individual characteristics may also influence journalistic coverage. However, there are only very few studies analyzing how these determinants affect the perceived influence of PR on journalistic content (Donsbach, 2004; Sallot \& Johnson, 2006; Sinaga \& Wu, 2007).

\section{Perceived Influence of PR on Journalistic Content}

Although a number of studies have analyzed the perceived influence of PR on journalistic content, their findings vary a great deal: For example, a survey of U.S. journalists reported that they perceive $44 \%$ of media coverage to be influenced by PR (Sallot $\&$ Johnson, 2006), 57.3\% of Australian travel journalists stated that press releases increasingly replace stories that were formerly based on journalistic research (Hanusch, 2012), and journalists working for leading Israeli media organizations perceived PR 
professionals to contribute to $73 \%$ of journalistic content (Reich, 2010). A summary of over 100 studies analyzing the relationship between PR and journalism found that $25 \%$ to $80 \%$ of journalistic content is influenced by PR such as press releases, press conferences, and conversations with PR professionals (Cameron et al., 1997).

There are three possible main reasons for these contradictory findings: First, these differences could be due to the fact that PR impact on journalistic coverage depends greatly on the attributes of the individual journalists, their work routines, and the media organizations they work for. Macro-level variables such as media laws, freedom of the press, and the state development of PR in specific countries also determine PR influence on journalistic content (Cameron et al., 1997; Hanitzsch et al., 2010; Lewis et al., 2008; Reich, 2010). Hence, to explain the variance in the findings regarding PR influence, there is a need for studies that analyze the impact of individual and organizational factors, as well as comparative research that takes possible macro-level determinants into account.

Another possible reason for these contradictory findings could be different conceptualizations of influence. The influence of PR on journalistic content comes not only in the form of providing press releases but can also manifest itself in multifaceted ways that are often hard to trace back; these less traceable forms include out-of-newsroom exchanges, as well as diverse forms of oral or electronic communications with PR professionals (Reich, 2010). Furthermore, PR influence manifests itself in various ways in journalistic content: Its influence can range from providing an idea for an article or arguments for a position, to being featured - either in a revised or unrevised form-in the final news item (Reber \& Berger, 2006; Reich, 2010). As the present study seeks to identify variables that determine how PR influence journalistic content, a broad concept of influence is necessary. Influence is therefore defined as the use of power to get things done (Mintzberg, 1983). The influence of PR on journalistic coverage manifests itself by gaining access, being heard, and shaping decisions (Reber \& Berger, 2006).

The final reason why findings in this research area differ so much may be due to the different ways that PR influence on journalistic content is assessed. For instance, journalists may estimate the degree of the influence of PR differently when asked about their own news coverage, compared with the news coverage of all journalists in a certain country (Sallot \& Johnson, 2006). Due to third person perceptions, journalists are likely to perceive their own content as being less susceptible to the influence of PR than the content of others. Moreover, different forms of assessment, such as closedended versus open-ended questions, Likert-type scales, or estimates of percentages may have contributed to the observed variance in the results.

Taken together, it is difficult to compare the findings on the influence of PR on journalistic content between studies. However, while the precise extent of this influence is not known, these studies present solid evidence that a considerable amount of journalistic news coverage contains information based on PR (Cameron et al., 1997; Curtin, 1999; Sallot \& Johnson, 2006).

Despite the large number of PR influencing journalistic content, journalists often assess their relationship to PR professionals as ambivalent or even as a necessary evil (Aronoff, 1975; Cameron et al., 1997; Sallot \& Johnson, 2006). Some journalists 
perceive PR to be unreliable or are annoyed by the large quantities of PR content that they receive on a daily basis (Hanusch, 2012; Weischenberg et al., 2006). This distrust of PR may be due to the fact that journalists have a public duty to inform the public, offer multiple viewpoints, and represent societal interests, while PR professionals are primarily charged with representing the interests of their clients (Aronoff, 1975; Riesmeyer, 2007; Ryan \& Martinson, 1988). However, despite this conflict of interests, some journalists assess PR quite positively, seeing these materials as providing a valuable - as well as cost- and time-effective - contribution to journalistic work (Curtin, 1999; Hanusch, 2012; Larsson, 2009; Sallot \& Johnson, 2006). Correspondingly, Gandy (1982, p. 62) argues that PR are "information subsidies," supplying journalists with information and helping them to save resources such as time and money. In light of these findings, we pose the following research question:

Research Question 1 (RQ1): To what extent do journalists perceive their journalistic content and the journalistic content of their peers to be affected by PR and how do they evaluate this influence?

\section{Determinants of the Perceived Influence of PR on Journalistic Content}

As outlined in the preceding section, research demonstrates that a moderate percentage of journalistic content is influenced by PR. Determining the impact of PR on journalistic work is, therefore, of great importance (Cameron et al., 1997; Donsbach, 2004; Weaver, 2015). Given the scant preliminary evidence on this particular question, we referred instead to research on the determinants of journalistic content in general. A literature review shows that individual attributes, journalistic routines, and organizational attributes were especially likely to contribute to the impact of PR on journalistic content (Hanitzsch et al., 2010; Preston, 2009; Reich \& Hanitzsch, 2013; Shoemaker, Eichholz, Kim, \& Wrigley, 2001).

\section{Influence of Journalists' Individual Attributes}

In this section, we elaborate on attributes of individual journalists that might determine the perceived influence of PR on news coverage. In general, individual attributes have been found to modestly affect journalistic content (Esser, 1998; Preston, 2009; Weaver \& Wilhoit, 1991); however, it remains unclear if the role of individual attributes remains the same in determining the influence of PR. A survey investigating how Indonesian journalists estimate the influence of PR on their news coverage provides some initial insights (Sinaga \& Wu, 2007): The authors demonstrated that, of all the surveyed journalists' demographic variables, only age negatively affected how frequently PR were used. However, in another study by Sinaga and Wu (2007), journalists working as reporters were found to use PR content more frequently than did news editors, indicating the one's professional position also played some role. We therefore ask: 
Research Question 2 (RQ2): How do journalist demographics and professional positions affect the perceived influence of PR on their journalistic content?

Role conceptions of journalists can directly translate into journalistic content and, hence, may also determine the use of PR (Patterson \& Donsbach, 1996; Shoemaker \& Reese, 1996; van Dahlen, de Vreese, \& Albæk, 2012). Cohen (1963) distinguishes between two core journalistic role conceptions: a neutral one, primarily aimed at providing factual information, and a participant one, which incorporates interpreting facts and presenting solutions to social issues. Subsequently, Weaver and Wilhoit $(1986,1996)$ identified three clusters of journalistic role conceptions: disseminators, interpreters, and adversaries. Journalists who see themselves as disseminators primarily aim to spread news that is of interest to the largest possible audience and to do so as quickly as possible. Interpreters try to analyze and explain complex problems, and adversaries focus on challenging societal elites. In subsequent studies, they added populist mobilizers, who try to present solutions to social grievances and to engage audiences to benefit the socially disadvantaged (Beam, Weaver, \& Brownlee, 2009; Weaver \& Willnat, 2012; Willnat \& Weaver, 2014; Weaver, Beam, Brownlee, Voakes, \& Wilhoit, 2007). Comparative studies have shown that similar journalistic role conceptions exist around the globe, although the degree of support for different conceptions differs by country (Hanitzsch, 2011; van Dahlen et al., 2012; Willnat, Weaver, \& Choi, 2013; Weischenberg et al., 2006).

Willnat et al. (2013) argue that "while a variety of measures by which journalists assess their profession exist in the literature, 'interpretive, ' disseminator,' and 'adversarial' journalistic roles are considered to be the ones that are linked most closely to journalistic competencies" (p. 173); these conceptions, including that of a populist mobilizer (Weaver \& Willnat, 2012; Willnat \& Weaver, 2014; Weaver et al., 2007), might be linked closely to journalists' use of PR in their content production (van Dahlen et al., 2012). However, research on the impact of journalistic role conceptions on PR influence is scarce. For instance, Indonesian journalists who perceived their journalistic role to be the one of an adversary reported relying less on PR, while no relationship was found between identifying as interpreters and the use of PR (Sinaga $\& \mathrm{Wu}, 2007)$. Based on these findings, one could reasonably assume that journalists who see their role as being adversaries against societal elites or as populist mobilizers might less readily incorporate PR materials than those who primarily aim to quickly and neutrally disseminate news and analyze events (Sinaga \& Wu, 2007; van Dahlen et al., 2012). We therefore propose the following two hypotheses:

Hypothesis 1a (H1a): Conceiving themselves as disseminators or interpreters increases the perceived influence of PR on their journalistic content.

Hypothesis 1b (H1b): Conceiving themselves as adversaries or populist mobilizers decreases the perceived influence of PR on their journalistic content.

Because relying on PR saves journalists time and money, it is logical that PR might exert a stronger influence on journalists with very limited resources (Donsbach, 2004; Reich \& Hanitzsch, 2013). One such group are freelance journalists, who earn too 
little to undertake cost- and time-intensive research (Meyen \& Springer, 2009). The increasing difficulty of making a living as a freelance journalist also means that nearly half of the freelance journalists in Germany have secondary employment in the PR sector. However, working as a so-called "PR journalist" (Koch \& Obermaier, 2014, p. 473 ) is not exclusively done by freelance journalists; staff journalists may also take secondary jobs in the PR sector.

Although becoming a PR journalist is financially rewarding, one's journalistic coverage may, naturally, be more strongly influenced by PR (Koch \& Obermaier, 2014; Obermaier \& Koch, 2015). First, because PR journalists produce PR themselves, they may assess PR more positively and, in turn, more readily use these materials for their journalistic work (Sinaga \& Callison, 2008). Second, a survey of freelance PR journalists in Germany found that participants could not prevent working on the same topics in their work as journalists and PR professionals (Koch \& Obermaier, 2014). Thus, journalistic content by PR journalists may logically be affected by ideas or information from the PR that they produce. Hence, we suppose the following:

Hypothesis 2a (H2a): Working as a freelance journalist increases the perceived influence of PR on their journalistic content.

Hypothesis 2b (H2b): Having a secondary employment in the PR sector increases the perceived influence of PR on their journalistic content.

\section{Influence of Journalistic Routines and Organizational Attributes}

Because both journalistic routines and organizational attributes influence journalists' professional autonomy and shape their news coverage, these characteristics might also affect their reliance on PR (Esser, 1998; Hanitzsch et al., 2010; Preston, 2009; Reich $\&$ Hanitzsch, 2013). Hence, this second section is concerned with these possible determinants of PR influence on journalistic content.

The impact of PR on journalists' news coverage may also be influenced by the beats that journalists mainly work for. Traditional soft news beats such as travel, health, fashion, beauty, and society have often been supposed to be more reliant on PR (Fürsich, 2012; Hanusch, 2012; Hanusch et al., 2015), while hard news beats such as politics, economics, and science are assumed to rely less on PR (Pincus et al., 1993; Reich, 2010; Weischenberg et al., 2006). We therefore propose the following:

Hypothesis 3a (H3a): Working for soft news beats rather than hard news beats increases the perceived influence of PR on journalistic content.

As mentioned in the preceding section, using PR as a source for news coverage helps journalists save time - a precious resource in most editorial departments (Beam et al., 2009; Curtin, 1999; Gandy, 1982; Weischenberg et al., 2006). Therefore, journalists who face time pressure in their daily work routines may more readily use PR in their journalistic content (Donsbach, 2004; Lewis et al., 2008; Sinaga \& Wu, 2007). Hence, we assume, 
Hypothesis 3b (H3b): Facing time pressure in the daily work routines increases the perceived influence of PR on journalistic content.

Because an over-reliance on PR can negatively affect the depth of investigation and, in turn, journalistic independence, formal or informal conventions on the use of PR such as regular discussions in editorial meetings or codes of conduct might be upheld in editorial departments (also see Hafez, 2002; Himelboim \& Limor, 2005). Knowing that they may face social sanctions if they fail to meet these normative expectations, journalists in such environments may rely less on PR (Ladendorf, 2012; Plaisance, Skewes, \& Hanitzsch, 2012). Therefore, we presume,

Hypothesis 3c (H3c): Newsroom conventions on the use of PR decrease the perceived influence of PR on their journalistic content.

Perceived constraints on journalistic autonomy when producing news coverage are another essential influence on the use of PR (Plaisance \& Deppa, 2009; Reich \& Hanitzsch, 2013). Such restrictions to the autonomy of journalistic work might be, for example, both supervision of the news coverage that one produces and economic interests of the publishers or the advertising departments (Soloski, 1989; Weaver et al., 2007). When deciding what role PR should play in their news coverage, journalists are expected to apply the professional standards demanded by their supervisors in the newsroom (Donsbach, 2004). If supervisors regularly review coverage to ensure that it is not excessively reliant on PR content, journalists are expected to rely less on PR to prevent sanctions. Furthermore, journalists are - at least to a certain degree — aware of the interests and influence of both advertisers and publishers (An \& Bergen, 2007; Hanitzsch \& Mellado, 2011; Hanusch et al., 2015; Reich \& Hanitzsch, 2013; Nyilasi \& Reid, 2011); anticipating the interests of advertisers and management has been shown to decrease journalists' perceived decisional autonomy in content production (Hanitzsch et al., 2010; Reich \& Hanitzsch, 2013). There is also some preliminary evidence that journalists bring their content into alignment with the anticipated interests of advertisers (Choi \& Park, 2011; Hagen, In der Au, \& Flämig, 2015). Especially when publishers, management, or the advertising department strive to acquire and retain lucrative advertising clients (Hanusch et al., 2015; Larsson, 2009), the influence of PR on news coverage may increase as journalists have a strong incentive to produce content that serves the interests of revenue sources (Curtin, 1999; Hagen et al., 2015; Larsson, 2009; McManus, 1995). This was explicitly borne out in a study of Indonesian journalists by Sinaga and $\mathrm{Wu}$ (2007): When managers or advertisers produced news coverage, PR were included more often than when news coverage was produced by independent sources. Based on this evidence, we propose the following hypotheses:

Hypothesis 4a (H4a): Newsroom counterchecking decreases the perceived influence of PR on journalistic content.

Hypothesis 4b (H4b): Journalists who consider the interests of publishers, managers, or advertisers experience an increased perceived influence of PR on their journalistic content. 
Finally, personal relationships between journalists and PR professionals could also affect PR influence on news coverage (Donsbach, 2004). Although journalists often assess their relationships with PR professionals rather negatively, over time, they might develop close personal working relations with individual PR professionals (Hanusch, 2012; Jeffers, 1977; Ryan \& Martinson, 1988; Sallot \& Johnson, 2006; Shin \& Cameron, 2003). Journalists who maintain close and trustworthy relationships with PR professionals may both be confronted more often with PR and may evaluate PR more positively; in turn, PR may affect their journalistic content more strongly (Aronoff, 1976; Curtin, 1999; Sallot \& Johnson, 2006). Therefore, we suppose,

Hypothesis 5 (H5): Close and trustworthy personal relationships between PR professionals and journalists increase the perceived influence of PR on their journalistic content.

\section{Influence of Media Organizations' Economic Attributes}

The economic attributes of media organizations such as media ownership, reach, financial situation, and competition - as well as the perception of those attributesmay also contribute to how PR is handled, changing the influence of PR on journalistic content (Curtin, 1999; McManus, 1995). Regarding media ownership, public broadcasting differs from privately owned media organizations in many ways, especially in the resources such as time and money that journalists have for the production of news content (Hanitzsch \& Mellado, 2011; also see Hanitzsch \& Berganza, 2012). Publications with only local or regional circulations also often lack the financial resources of publications with national or international distribution, meaning that the former may therefore rely on PR to a greater extent than the latter. However, at the same time, PR activities on the national or international level might be more professionalized, making how the reach of media products affects PR influence on news coverage unclear (also see Curtin, 1999; Franklin, 2006; Lewis et al., 2008). Moreover, the financial situation of a media organization could affect journalists' reliance on PR. As touched upon when comparing public and private media ownership, a poor financial situation may make it more likely that journalists would accept free materials from PR professionals; empirical findings on this relationship are, however, scarce. Finally, the degree of competition media organizations are faced with could determine the influence of PR on news coverage, although arguments could be made for influence in both directions: While strong competition may cause more economic pressure, enticing journalists to rely more on PR, the presence of strong competition could also encourage media organizations to strive to provide content that meets high journalistic standards, thereby putting pressure on them to reduce the role of PR in their news coverage (McManus, 1995). Hence, the last research question is as follows:

Research Question 3 (RQ3): How do the ownership, reach, competition, and the financial situation of media organizations affect the perceived influence of PR on their journalistic content? 


\section{Method}

\section{Sampling and Participants}

To test the hypotheses and to provide answers to the research questions, we conducted a quantitative online survey. In order to create a heterogenic sample of German journalists, we used "Zimpel Online," a comprehensive (email-) address database providing around 90,000 weekly updated contacts to editorial departments and journalists. We deleted contact information of persons who do not work for journalistic publications (e.g., in corporate publishing instead) as well as of individuals who do not work journalistically (e.g., having an organizational or technical job at a journalistic medium instead such as in marketing or program planning; Weischenberg et al., 2006). For each initial letter of the last name, we randomly selected 500 contacts (whenever possible) and removed duplicates as well as obviously incorrect addresses. Finally, a total of 7,874 journalistic contacts remained in the random sample. In November 2013, we sent emails containing an invitation to these journalists. A total of 835 journalists participated in the survey, representing a response rate of $10.60 \%$.

\section{Measures}

The questionnaire consisted of four subsections measuring (1) journalists' individual attributes, (2) journalistic routines and organizational attributes, (3) economic attributes of media organizations, as well as (4) the perception and evaluation of the influence of PR on journalistic content. In the first section, participants indicated their demographics (sex, age, education) as well as their professional positions. Furthermore, we inquired about their employment status and whether they have a secondary employment in the PR sector (we provided corporate publishing as an example, because journalists often fail to consider it as PR work; Koch \& Obermaier, 2014). Journalistic role conceptions were measured by four items (Weaver et al., 2007; Willnat et al., 2013; Weischenberg et al., 2006): "informing the audience as neutrally and precisely as possible" $(M=4.39, S D=0.80)$, "analyzing and interpreting complex issues" $(M=4.52, S D=0.72)$, "criticizing grievances in society" $(M=$ $3.49, S D=1.19)$, and "getting involved for disadvantaged people in society" $(M=$ $2.80, S D=1.26,5$-point Likert-type scales, $1=$ strongly disagree to $5=$ strongly agree).

In the section on journalistic routines and organizational attributes, participants specified for which journalistic beat they (mainly) work. Also, we inquired to what degree journalists experience time pressure in their daily work routines ("When working journalistically I experience a great time pressure"; $M=3.71, S D=1.06$; Reich \& Hanitzsch, 2013; Weischenberg et al., 2006). We also asked about the application of newsroom conventions on the use of PR: "dealing with PR is discussed in editorial meetings" $(M=2.78, S D=1.35)$ and "ethical codes for dealing with PR are applied in the editorial department" $(M=3.40, S D=1.41$; also see Hanitzsch et al., 2010; Plaisance et al., 2012; Reich \& Hanitzsch, 2013). Furthermore, participants had 
to indicate their perceived constraints in journalistic autonomy: First, they indicated whether their journalistic content is counterchecked by supervisors $(M=2.71, S D=$ 1.59). Second, participants had to rate the extent of their agreement to the following two items: "I consider publishers' or managers' interests when producing journalistic content" $(M=2.84, S D=1.32)$ and "I bring my journalistic content into agreement with interests of the advertising department" $(M=2.08, S D=1.25$; also see Hanitzsch \& Mellado, 2011; Hanitzsch et al., 2010; Nyilasi \& Reid, 2011; Reich \& Hanitzsch, 2013). Also, the quality of personal relationships with PR professionals was assessed with semantic differentials: distanced to close $(M=2.78, S D=0.90)$ and not trustworthy to trustworthy $(M=3.26, S D=0.90)$. All items were measured on 5-point Likert-type scales $(1=$ strongly disagree to 5 = strongly agree; also see Neijens \& Smit, 2006; Shin \& Cameron, 2003).

In the third section, participants indicated whether they (mainly) work for public service media or private media and stated if their main employer is a local/regional publication or a publication with (inter-) national reach. Furthermore, the assessment of the overall financial situation of the media organization they (mainly) work for (positive to negative; $M=2.90, S D=1.09$ ) as well as the perceived competition the media organization is confronted with was measured (5-point Likert-type scales; no competition to high competition; $M=3.55, S D=1.20$; also see Beam et al., 2009; Hanitzsch \& Mellado, 2011).

In the fourth section, participants estimated which percentage of their own journalistic content is "free of PR," "influenced by PR," and "consisting of unrevised PR." In addition, they assessed the portion of journalistic coverage in Germany that is "free of PR" (each item ranging from $0 \%$ to $100 \%$ ). Moreover, participants rated their agreement to the items "PR or professionals have a great impact on my journalistic content" $(M=2.40, S D=1.16)$, "PR can easily be placed in journalistic publications $(M=3.53$, $S D=0.97)$, and "My journalistic work would be much harder without PR" (5-point Likert-type scales; $M=2.68, S D=1.26$; also see Hanusch, 2012; Sallot \& Johnson, 2006; Sinaga \& Wu, 2007).

\section{Results}

\section{Perception and Evaluation of PR' Influence on Journalistic Content}

The sample consisted of a total of 835 journalists, of which, $61.5 \%$ are male, with a mean age of 45.02 years $(S D=10.41$ years $) ; 80.9 \%$ had a university degree and already had 18.11 years $(S D=10.01$ years) of experience working journalistically. Hence, in these characteristics, the sample resembles the structure of journalists in Germany former studies revealed (e.g., Weischenberg et al., 2006). The first research question (RQ1) was concerned with journalists' perceived influence of PR on journalistic content and with their evaluation of this impact. When asked about their own work, participants considered more than two thirds of their journalistic coverage to be free of PR $(M=68.43 \%, S D=26.30 \%)$. Correspondingly, about one third of their journalistic content was perceived to be influenced by $\operatorname{PR~}(M=27.95 \%$, 
$S D=23.51 \%) ; 5.31 \%(S D=10.59 \%)$ of their news coverage was, on average, said to consist of unrevised PR.

Accordingly, a majority (58.2\%) of the participants (fully) disagreed that PR have a great impact on their journalistic work in general. ${ }^{1}$ Yet, $18.7 \%$ (fully) agreed that PR influence their news coverage to a great extent. Nevertheless, PR materials are not assessed as entirely negative: One third (29.4\%) of the participants (fully) agreed that PR materials facilitate the production of journalistic content; $48 \%$ did not agree on that (at all). In addition, half of the participants (fully) consented that it is easy for PR professionals to place PR in journalistic publications (55.7\%); only $13.4 \%$ (fully) refused that PR can easily be placed in news coverage.

In contrast to their estimations concerning the influence of PR on their own work, participants considered less than half of the news coverage published in Germany to be free of PR influence ( $M=44.76 \%, S D=20.98 \%)$. Therefore, they assessed their own journalistic content to be less determined by PR than the German news coverage in general, $t(756)=26.10, p<.001, d=0.99 .^{2}$ This considerable difference may be due to a third person perception: People believe that communications exert a stronger impact on others than on themselves (Atwood, 1994; Davison, 1983; Gunther, 1991; Gibbon \& Durkin, 1995). In this case, journalists believe that their colleagues are more susceptible to PR messages than they are. This is in line with third person research in general, showing that people believe that they are less likely affected by persuasive communication than others (Perloff, 1999). This result can be explained by an illusory superiority stating that individuals tend to ascribe themselves more positive characteristics and behaviors than others (Alicke, 1985; Hoorens \& Harris, 1998). The third person perception is more pronounced when the media influence is perceived as being undesirable (Atwood, 1994; Perloff, 1999); because journalists view the influence of PR rather negatively, this might explain the large effect sizes (Aronoff, 1975; Hanusch, 2012). Nevertheless, the question remains whether participants overestimate PR influence on other journalists or whether they underestimate the PR influence on themselves. In the first scenario, journalists perceive others to be more dependent on PR than they really are and, thus, underestimate others' independence. In the second scenario, journalists overrate the independence of their news coverage from PR to keep a positive self-perception. To provide a detailed answer to this question, further research is needed.

Taken together, to answer RQ1, German journalists perceive a considerable amount of their own journalistic content and an even greater amount of the overall news coverage in Germany to be influenced by PR. However, this influence is not perceived entirely negative, because journalists also appreciate $\mathrm{PR}$ as a valuable contribution to their work.

\section{Journalistic Routines and Organizational Attributes}

Because journalistic routines and organizational attributes are considered to be potential determinants of PR influence on journalistic content, the respective variables are 
described separately first. Time pressure in journalists' daily work routines as well as newsroom conventions may affect their dealing with PR. A total of $61.6 \%$ of the participants (strongly) agreed that they have to work under a great time pressure, whereas only $13.1 \%$ (strongly) opposed that statement. About one third of the participants (strongly) stated that dealing with PR is discussed in editorial meetings (34.1\%); yet, $44.5 \%$ of the participants do not discuss the handling of PR the editorial department. However, half of the participants reported that ethical codes concerning the handling of PR are applied in the editorial department they (mainly) work for $(53.2 \%)$; one third (strongly) disagreed that these codes are valid in their editorial department $(27.2 \%)$.

Concerning restrictions to the autonomy of journalistic work, news coverage of one third of the participants is counterchecked by their supervisors $(33.9 \%)$, whereas half of the participants (fully) agreed that supervisors do not control their work $(52.9 \%)$. Moreover, our data show that $41.0 \%$ of the participants (fully) agree to not consider the interests of publishers or managers when producing journalistic content. Yet, $32.4 \%$ of the participants (fully) agreed that they take those interests into account in their news coverage. Furthermore, two thirds $(66.4 \%)$ of the journalists (fully) agreed that they do not consider the interests of the advertising department with their journalistic content. However, $16.1 \%$ of the participants (strongly) consented to bring their journalistic content into agreement with interests of the advertising department. Hence, economic interests are indeed taken into consideration for the production of journalistic content (also see Hanusch et al., 2015).

Finally, we find that the personal relationships between journalists and PR professionals are perceived positively: $37.8 \%$ of journalists stated that their relationship with PR professionals is (very) trustworthy; however, only $15.9 \%$ of the participants do not have a trustworthy relation to PR professionals (at all). In addition, 16.8\% of the participants assessed their personal relationships with PR professionals as (very) close, whereas one third (30.9\%) described the relationships with PR professionals as (very) distanced.

\section{Determinants of the Perceived Influence of PR on Journalistic Content}

This study was mainly interested in explaining determinants of the perceived influence of PR on journalistic content. Therefore, we calculated a linear ordinary least squares (OLS) regression (forced entry) with the estimated percentage of journalists' own news content free of PR as dependent variable. We decided to include this variable because it showed an adequate variance and covers all forms of PR influence on journalistic content, from determining the idea of a news item up to delivering parts of the actual journalistic content or being included unaltered. Journalists' individual attributes, journalistic routines, and organizational attributes, as well as economic attributes of the media organizations the participants (mainly) work for were entered as predictor variables (Table 1). 
Table I. Linear Regression (OLS) Predicting the Percentage of Own Journalistic Content Assessed to be free of PR.

\begin{tabular}{|c|c|c|}
\hline Predictors & $\begin{array}{l}\text { Unstandardized } \\
\text { coefficients B (SE) }\end{array}$ & $\begin{array}{l}\text { Standardized } \\
\text { coefficients } \beta\end{array}$ \\
\hline \multicolumn{3}{|l|}{ Journalists' individual attributes } \\
\hline $\operatorname{Sex}(0=$ male, $\mathrm{I}=$ female $)$ & $-1.10(2.11)$ & -.02 \\
\hline Age & $.01(0.10)$ & .01 \\
\hline University degree $(0=$ no, $\mathrm{I}=$ yes $)$ & $-2.22(2.5 \mathrm{I})$ & -.03 \\
\hline Journalistic position ( 0 = non leading, $\mathrm{I}=$ leading $)$ & $2.76(2.06)$ & .05 \\
\hline Journalistic role conception: Disseminator & $2.62(1.36)$ & $.08^{\dagger}$ \\
\hline Journalistic role conception: Interpreter & $-1.84(1.56)$ & -.05 \\
\hline Journalistic role conception: Adversary & $1.53(1.04)$ & .07 \\
\hline Journalistic role conception: Populist mobilizer & $1.83(0.93)$ & $.09 *$ \\
\hline Employment status $(0=$ employed, $\mathrm{I}=$ freelance $)$ & $-6.94(3.64)$ & $-.07 \dagger$ \\
\hline Secondary employment PR $(0=$ no, I = yes $)$ & $-7.4 I(2.96)$ & $-.10^{*}$ \\
\hline \multicolumn{3}{|l|}{$R^{2}=.14^{* * *}$} \\
\hline \multicolumn{3}{|l|}{ Journalistic routines and organizational attributes } \\
\hline Beat $(0=$ hard topics, $I=$ soft topics $)$ & $-.53(.31)$ & $-.06 \dagger$ \\
\hline Time pressure in journalistic work & $-1.61(.92)$ & $-.07 \dagger$ \\
\hline Dealing with PR discussed in editorial meetings & $1.01(.74)$ & .05 \\
\hline $\begin{array}{l}\text { Ethic codes for dealing with PR applied in } \\
\text { newsroom }\end{array}$ & $1.59(.74)$ & $.09 *$ \\
\hline Countercheck by supervisors & $.91(.64)$ & .06 \\
\hline Interests of publishers or managers considered & $-2.06(.87)$ & $-.10 *$ \\
\hline $\begin{array}{l}\text { Content in accordance with advertising } \\
\text { department }\end{array}$ & $-5.53(.92)$ & $-.27 * * *$ \\
\hline Close relationship with PR professionals & $-2.75(1.20)$ & $-.10 *$ \\
\hline Trustworthy relationship with PR professionals & $-2.99(1.22)$ & $-.10^{*}$ \\
\hline$R^{2}=.16 * * *$ & & \\
\hline \multicolumn{3}{|l|}{ Economic attributes of media organization } \\
\hline Ownership ( 0 = public service, $I$ = private) & $.14(.41)$ & $.0 \mathrm{I}$ \\
\hline Local/regional (0), (inter-) national publication (I) & $.50(.5 \mathrm{I})$ & .04 \\
\hline Financial situation & $.41(0.93)$ & .02 \\
\hline Competition & $.65(0.83)$ & .03 \\
\hline \multicolumn{3}{|l|}{$R^{2}=.003$} \\
\hline Intercept & $83.10 * * *(11.05)$ & \\
\hline \multicolumn{3}{|l|}{ Total $R^{2}=.30$} \\
\hline Total $R_{\text {Adjust }}^{2}=.27$ & & \\
\hline
\end{tabular}

Note. Variance Inflation Factor (VIF) $\leq 1.77$, Durbin-Watson $=1.94 . \mathrm{OLS}=$ ordinary least squares; $\mathrm{PR}=$ public relations.

$t_{p}<.10 . * p<.05 .{ }^{* *} p<.01 . * * * p<.001$.

RQ2 inquired how demographics as well as the professional position affect the (perceived) influence of PR on journalistic content. However, neither sex $(\beta=-.02$, 
$p=.60)$, age $(\beta=.01, p=.91)$, education $(\beta=-.03, p=.38)$, nor participants' professional position $(\beta=.05, p=.18)$ significantly predicted the amount of their journalistic content free of PR. Referring to H1a, sharing the journalistic role conception of a neutral disseminator slightly decreased the influence of PR on journalistic content $(\beta=.08, \mathrm{p}=.05)$, which was contrary to our expectations, whereas the primary communicative goal to interpret news did not affect the influence of PR on journalistic content at all $(\beta=-.05, p=.24)$. Hence, there is no support for H1a. Also, journalists' role conception as adversary did not predict the portion of journalistic coverage free of $\operatorname{PR}(\beta=.07, p=.14)$. However, the journalistic role conception of a populist mobilizer, aiming to engage themselves for the disadvantaged in society decreased the impact of PR $(\beta=.09, p=.05)$. Therefore, H1b can only be partially supported.

On the contrary, employment status $(\beta=-.07, p=.06)$ increased the influence of PR; however, this support for $\mathrm{H} 2 \mathrm{a}$ is only on a $p<.10$ significance level. A secondary employment in the PR sector $(\beta=-.10, p=.01)$ also increased the impact of PR, supporting $\mathrm{H} 2 \mathrm{~b} .{ }^{3} \mathrm{PR}$ journalists might be less inhibited to use PR for their journalistic coverage and also reuse thematic ideas of their PR activities for their journalistic work (Koch \& Obermaier, 2014; Obermaier \& Koch, 2015).

Both mainly working for soft compared with hard news beats $(\beta=-.06, p=.09)$ and experiencing time pressure $(\beta=-.07, p=.08)$ slightly increased the perceived influence of PR on news coverage; these effects predicted by $\mathrm{H} 3 \mathrm{a}$ and $\mathrm{H} 3 \mathrm{~b}$, however, emerged only on a $p<.10$ significance level. In contrast, the newsroom convention of discussing on how to deal with (current) PR did not influence the perceived composition of their journalistic work $(\beta=.05, p=.17)$; the application of ethical codes concerned with the handling of PR, however, positively affected the portion of the own journalistic coverage free of PR $(\beta=.09, p=.03)$. Thus, there is only partial support for H3c. A regular countercheck of journalistic content by supervisors did not affect the influence of PR $(\beta=.06, p=.16)$; hence, there is no support for $\mathrm{H} 4 \mathrm{a}$. However, taking into account interests of publishers or managers $(\beta=-.10$, $p=.02)$ and considering the interests of advertisers $(\beta=-.27, p<.001)$ increased the perceived influence of PR, supporting H4b. Also, the personal relationships with PR professionals affected the perceived PR influence: The closer $(\beta=-.10, p=.02)$ and more trustworthy $(\beta=-.10, p=.01)$ the personal relationships between journalists and PR professionals were, the greater was the impact of PR on their journalistic work, supporting H5.

RQ3 was concerned with the degree to which economic attributes of media organizations determine the influence of PR. However, working for public service broadcasting compared with private media organizations did not affect the perceived influence of PR $(\beta=.01, p=.73)$; also, working for a local/regional compared with an (inter-) national media organization yielded no effect $(\beta=.04, p=.33)$. The same applied to both the perceived financial situation of the media organization $(\beta=.02, p=.66)$ and the assessment of the degree of competition faced by the media organization $(\beta=.03$, $p=.44)$. Hence, economic attributes of media organizations did not affect the perceived influence of PR in this study. 


\section{General Discussion}

The present study focused on the perceived influence of PR on journalists' news coverage. By identifying determinants of the perceived influence of PR on journalistic content, it shed light on why findings on how PR influence journalistic content vary so much (Cameron et al., 1997; Shoemaker \& Reese, 1996). This builds on previous research that only focused either on specifying the amount of news coverage influenced by PR or on describing different aspects of the relationships between journalists and PR professionals (Jo \& Kim, 2004; Lewis et al., 2008; Shin \& Cameron, 2003; Waters et al., 2010). The present study also explained how the determinants of the impact of PR on journalistic content act both on the individual and organizational level, incorporating constraints that journalists face within the media organizations they work for (Hanitzsch \& Mellado, 2011; Weaver, 2015). By testing these determinants together in a single model, the results of the present study were able to compare of the strength of their impact on the influence of PR on journalistic content.

Overall, while journalists considered the influence of PR on their coverage to be moderate, assessing about one third of their own news coverage to be affected by PR, they estimated far more of the German news coverage in general to be influenced by PR (Cameron et al., 1997; Sallot \& Johnson, 2006). This third person perception is due to an illusory superiority, by which journalists minimize the influence of PR on their own news coverage while assuming that others use PR more (Davison, 1983; Gunther, 1991; Hoorens \& Harris, 1998). However, PR was not assessed as purely negative, as one third of the participants considered PR to be a useful information subsidy (Aronoff, 1975; Gandy, 1982).

This study shows that PR' influence on news coverage is affected by both the attributes of individual journalists and by journalistic work routines (Shoemaker \& Reese, 1996). With regard to journalists' individual-level attributes, neither demographics nor professional position were associated with the use of PR. However, a journalistic role conception of populist mobilizer was associated with less influence of PR on one's news coverage. Trying to more actively shape news coverage, these populist mobilizers may be more aware of the usage of PR and be more wary of relying on it. This result empirically supports the idea that journalistic role conceptions can directly affect journalists' use of PR materials (Donsbach, 2004; Shoemaker \& Reese, 1996; van Dahlen et al., 2012). In contrast, being a journalist with secondary employment in the PR sector was associated with a greater influence of PR. This finding could reflect the scarcity of resources that PR journalists face, their more positive attitude toward $\mathrm{PR}$, or an inadvertent effect of producing PR content and news reporting on the same topics (Koch \& Obermaier, 2014; Obermaier \& Koch, 2015). In sum, individual-level variables do affect the impact PR materials have on journalistic content. These effects were shown to mainly stem from an active journalistic role conception or from secondary employment in the field of PR.

Concerning the influence of work routines in the editorial departments for which journalists work, neither counterchecks by supervisors nor the convention of a regular discussion of how PR content is being handled correlated with the influence of PR 
(Hafez, 2002; Himelboim \& Limor, 2005). However, in cases where journalistic ethical codes for the handling of PR were applied in the editorial department, PR had less influence on news coverage. In contrast, mainly working for soft news beats was associated with more influence of PR. Also, journalists who needed to cater to the economic interests of publishers or management, or who took into account the interests of advertising clients, relied more strongly on PR in creating their coverage (Hanusch et al., 2015). Furthermore, having close and trustworthy personal relationships with PR professionals increased PR influence on journalistic content. These findings offer empirical evidence that the personal relationships between journalists and PR professionals can affect journalistic content (Curtin, 1999; Jo \& Kim, 2004; Pincus et al., 1993; Shin \& Cameron, 2003). Furthermore, certain journalistic routines and organizational attributes may also affect the impact of PR on news coverage; in particular, close and trustworthy relationships with PR professionals, editorial conventions, and taking into account the interests of publishers and advertising clients yielded substantial effects.

Finally, the economic attributes of media organizations such as ownership, financial situation, and reach of publications were not significantly associated with the level of influence PR had on news coverage. However, this may be due to the fact that we measured these attributes indirectly, through journalists' perceptions. Journalists may not actually be fully aware of the situation, instead inferring it based on constraints that they experience in their work routines. Therefore, it is important to replicate this study using objective measures to assess the economic attributes of the media organizations.

While these results do contribute to this area of research, they also have certain limitations. First, although our random sample of journalists was drawn from a comprehensive directory of German journalists, and our sample shared the same demographic profile of the population of interest (Weischenberg et al., 2006), we cannot be sure that our sample was entirely representative. The rather low response rate of $10.6 \%$ further limits the representativeness of the sample, because journalists sharing certain characteristics may have systematically declined to take part in the survey. Second, using self-reports from journalists to gather data can be problematic, and the honesty of even well-meaning participants must be assessed critically. Journalists are sensitive about their use of PR, especially as they generally view PR in a negative light, and may have been tempted (even unconsciously) to minimize their reliance on PR (Aronoff, 1975; Hanusch, 2012). Although we hoped that our online survey methodology and the assurance of anonymity would decrease participants' likelihood to be dishonest, even participants who tried to be honest might lack the ability to assess themselves accurately and might, therefore, view themselves in an overly positive light, underestimating the influence of PR on their own journalistic content (Kewley, Larson, \& Miyoshi, 2007; Reich, 2010). Moreover, journalists may not always be aware of the interests and actions of the advertising department or the management. We also hoped that because we were mainly interested in identifying the determinants of the perceived influence of PR, as opposed to journalists' assessment of the actual influence of PR on news coverage, this source of bias would be minimized-however, it could not 
be removed entirely. Finally, as our results are limited to a German context, it would be intriguing to replicate this study in other countries.

Although our results provided preliminary evidence for the determinants of the influence of PR on journalistic content, several questions remain. First, the present study did not differentiate between various ways that PR could influence news coverage, such as suggesting ideas, promoting specific issues for coverage, or shaping the argumentation. While our rather broad conceptualization including every possible PR influence that journalists could experience was adequate for the present study — which was one of the first to test the determinants of the influence of PR on journalistic content - it would be valuable to determine what factors are associated with specific types of influence. Specifically, we believe that the influence that PR was found to have on the journalistic content produced by freelance and PR journalists, as well as the influence of personal relationships between journalists and PR professionals, would both be fruitful areas to explore in greater detail. Also, future studies could test for other variables possibly influencing the PR impact on journalistic content (e.g., professional education or work-related stress).

In sum, the present study demonstrated that PR do affect journalistic content, journalists are aware of this influence, and the extent this influence is strongly associated with several individual and organizational attributes. We hope that this study will raise awareness regarding the relationship between journalism and PR and will inspire more research on what factors determine PR' deep impact on journalism.

\section{Declaration of Conflicting Interests}

The author(s) declared no potential conflicts of interest with respect to the research, authorship, and/or publication of this article.

\section{Funding}

The author(s) received no financial support for the research, authorship, and/or publication of this article.

\section{Notes}

1. Agreement means checking 4 or 5, while disagreement means checking 1 or 2 on a 5-point scale.

2. Mean and standard deviation of the perceived percentage of the own news coverage free of public relations (PR; $M=68.35 \%, S D=26.30 \%$ ) slightly differ from the ones reported above. This is due to the fact that only participants are taken into account that provided an assessment of the portion of journalistic content free of PR in Germany.

3. A total of $16.8 \%$ of the participants have a secondary employment in the PR sector.

\section{References}

Alicke, M. D. (1985). Global self-evaluation as determined by the desirability and controllability of trait adjectives. Journal of Personality and Social Psychology, 49, 1621-1630. doi:10.1037//0022-3514.49.6.1621 
An, S., \& Bergen, L. (2007). Advertiser pressure on daily newspapers: A survey of advertising sales executives. Journal of Advertising, 36, 111-121. doi:10.2753/JOA0091-3367360208

Aronoff, C. (1975). Credibility of public relations for journalists. Public Relations Review, 1, 45-56. doi:10.1016/S0363-8111(75)80023-3

Aronoff, C. (1976). Predictors of success in placing releases in newspapers. Public Relations Review, 2, 43-57. doi:10.1016/S0363-8111(76)80023-9

Atwood, E. L. (1994). Illusions of media power: The third-person effect. Journalism Quarterly, 71, 269-281. doi:10.1177/107769909407100202

Beam, R. A., Weaver, D. H., \& Brownlee, B. J. (2009). Changes in professionalism of U.S. journalists in the turbulent twenty-first century. Journalism \& Mass Communication Quarterly, 86, 277-298. doi:10.1177/107769900908600202

Breed, W. (1955). Social control in the newsroom: A functional analysis. Social Forces, 33, 326-335. doi: $10.2307 / 2573002$

Cameron, G. T., Sallot, L. M., \& Curtin, P. A. (1997). Public relations and the production of news: A critical review and a theoretical framework. In B. Burleson (Ed.), Communication yearbook (pp. 111-155). Thousand Oaks, CA: SAGE.

Cho, S. (2006). The power of public relations in media relations: A national survey of health PR practitioners. Journal of Mass Communication Quarterly, 83, 563-580. doi: $10.1177 / 107769900608300306$

Choi, J., \& Park, S. (2011). Influence of advertising on acceptance of press releases. Public Relations Review, 37, 106-108. doi:10.1016/j.pubrev.2010.09.010

Cohen, B. C. (1963). The press and foreign policy. Princeton, NJ: Princeton University Press.

Curtin, P. A. (1999). Reevaluating public relations information subsidies: Market-driven journalism and agenda-building theory and practice. Journal of Public Relations Research, 11, 53-90. doi:10.1207/s1532754xjprr1101_03

Davison, W. P. (1983). The third-person effect in communication. Public Opinion Quarterly, 47, 1-15. doi:10.1086/268763

Donsbach, W.(2004). Psychology of news decisions. Factors behind journalists' professional behavior. Journalism: Theory, Practice and Criticism, 5, 131-157. doi:10.1177/146488490452002

Esser, F. (1998). Editorial structures and work principles in British and German newsrooms. European Journal of Communication, 13, 375-405. doi:10.1177/0267323198013003004

Ettema, J. E., Whitney, D. C., \& Wackman, D. B. (1987). Professional mass communicators. In C. R. Berger \& S. H. Chaffee (Eds.), Handbook of communication science (pp. 747-780). Beverley Hills, CA: SAGE.

Franklin, B. (2006). Local journalism and local media: Making the local news. London, England: Routledge.

Fürsich, E. (2012). Lifestyle journalism as popular journalism: Strategies for evaluating its public role in the era of globalization. Journalism Practice, 6, 12-25. doi:10.1080/17512786. 2011.622894

Gandy, O. (1982). Beyond agenda setting: Information subsidies and public policy. New York, NY: Ablex.

Gibbon, P., \& Durkin, K. (1995). The third person effect: Social distance and perceived media bias. European Journal of Social Psychology, 25, 597-602. doi:10.1002/ejsp.2420250509

Gunther, A. C. (1991). What we think others think: Cause and consequence in the third-person effect. Communication Research, 18, 355-372. doi:10.1177/009365091018003004

Hafez, K. (2002). Journalism ethics revisited: A comparison of ethics codes in Europe, North Africa, the Middle East, and Muslim Asia. Political Communication, 19, 225-250. doi:10.1080/10584600252907461 
Hagen, L. M., In der Au, A.-M., \& Flämig, A. (2015, May 25). Effects of advertiser pressure on press coverage: How Germany's leading political magazines synchronize news and ads. Paper presented at the Annual Conference of the International Communication Association, San Juan, Puerto Rico.

Hanitzsch, T. (2011). Populist disseminators, detached watchdogs, critical change agents and opportunist facilitators: Professional milieus, the journalistic field and autonomy in 18 countries. The International Communication Gazette, 73, 477-494. doi:10.1177/1748048511412279

Hanitzsch, T., Anikina, M., Berganza, R., Cangoz, I., Coman, M., Hamada, B., . . . Yuen, K. W. (2010). Modeling perceived influences on journalism: Evidence form a crossnational survey of journalists. Journalism \& Mass Communication Quarterly, 87, 5-22. doi:10.1177/107769901008700101

Hanitzsch, T., \& Berganza, R. (2012). Explaining journalists' trust in public institutions across 20 countries: Media freedom, corruption, and ownership matter most. Journal of Communication, 62, 794-814. doi:10.1111/j.1460-2466.2012.01663.x

Hanitzsch, T., \& Mellado, C. (2011). What shapes the news around the world? How journalists in eighteen countries perceive influences on their work. The International Journal of Press/ Politics, 16, 404-426. doi:10.1177/1940161211407334

Hanusch, F. (2012). Travel journalists' attitudes toward public relations: Findings from a representative survey. Public Relations Review, 38, 69-75. doi:10.1016/j.pubrev.2011.10.001

Hanusch, F., Hanitzsch, T., \& Lauerer, C. (2015). 'How much love are you going to give this brand?' Lifestyle journalists on commercial influences in their work. Journalism: Theory, Practice and Criticism. Advance online publication. doi:10.1177/1464884915608818

Himelboim, I., \& Limor, Y. (2005, May 29). The journalistic societal role: An international comparative study of 242 codes of ethics. Paper presented at the Annual Conference of the International Communication Association, New York, NY.

Hoorens, V., \& Harris, P. (1998). Distortions in reports of health behaviors: The time span effect and illusory superiority. Psychology and Health, 13, 451-466. doi:10.1080/08870449808407303

Jeffers, D. W. (1977). Performance expectations as a measure of relative status of news and PR people. Journalism Quarterly, 54, 299-306. doi:10.1177/107769907705400210

Jo, S., \& Kim, Y. (2004). Media or personal relations? Exploring media relations dimensions in South Korea. Journal of Mass Communication Quarterly, 81, 292-306. doi:10.1177/107769900408100205

Kewley, S. B., Larson, G. E., \& Miyoshi, D. K. (2007). Social desirability effects on computerized and paper-and-pencil questionnaires. Computers in Human Behavior, 23, 463-477. doi:10.1016/j.chb.2004.10.020

Klinenberg, E. (2005). Convergence: News production in a digital age. The Annals of the American Academy of Political and Social Science, 597, 48-64. doi:10.1177/0002716204270346

Koch, T., \& Obermaier, M. (2014). Blurred lines. German freelance journalists with secondary employment in public relations. Public Relations Review, 40, 473-482. doi:10.1016/j. pubrev.2014.02.006

Ladendorf, M. (2012). Freelance journalists' ethical boundary settings in information work. Nordicom Review, 33, 83-98. doi:10.2478/nor-2013-0006

Larsson, L. (2009). PR and the media: A collaborative relationship? Nordicom Review, 30, 131-147.

Lewis, J., Williams, A., \& Franklin, B. (2008). A compromised fourth estate? UK news journalism, public relations and news sources. Journalism Studies, 9, 1-20.doi:10.1080/14616700701767974

McManus, J. (1995). A market-based model of news production. Communication Theory, 5, 301-338. doi:10.1111/j.1468-2885.1995.tb00113.x 
Meyen, M., \& Riesmeyer, C. (2012). Service providers, sentinels, and traders: Journalists' role perceptions in the early twenty-first century. Journalism Studies, 13, 386-401. doi:10.1080/ 1461670X.2011.602909

Meyen, M., \& Springer, N. (2009). Freie Journalisten in Deutschland. Ein Report [Freelance journalists in Germany. A report]. Konstanz, Germany: UVK.

Mintzberg, H. (1983). Power in and around organizations. Englewood Cliffs, NJ: Prentice Hall.

Neijens, P., \& Smit, E. (2006). Dutch public relations practitioners and journalists: Antagonists no more. Public Relations Review, 32, 232-240. doi:10.1016/j.pubrev.2006.05.015

Nyilasi, G., \& Reid, L. N. (2011). Advertiser pressure and the personal ethical norms of newspaper editors and ad directors. Journal of Advertising Research, 51, 538-551. doi:10.2501/ JAR-51-3-538-552

Obermaier, M., \& Koch, T. (2015). Mind the gap: Consequences of inter-role conflicts of freelance journalists with secondary employment in the field of PR. Journalism: Theory, Practice and Criticism, 16, 615-629. doi:10.1177/1464884914528142

Patterson, T. E., \& Donsbach, W. (1996). News decisions: Journalists as partisan actors. Political Communication, 13, 455-468. doi:10.1080/10584609.1996.9963131

Perloff, R. M. (1999). The third person effect: A critical review and synthesis. Media Psychology, 1,353-378. doi:10.1207/s1532785xmep0104_4

Pincus, D. J., Rimmer, D., Rayfield, R. E., \& Cropp, F. (1993). Newspaper editors' perceptions of public relations: How business, news and sports editors differ. Journal of Public Relations Research, 5, 27-45. doi:10.1207/s1532754xjprr0501_02

Plaisance, P. L., \& Deppa, J. A. (2009). Perceptions and manifestations of autonomy, transparency and harm among U.S. newspaper journalists. Columbia, SC: The Association for Education in Journalism and Mass Communication.

Plaisance, P. L., Skewes, E. A., \& Hanitzsch, T. (2012). Ethical orientations of journalists around the globe: Implications from a cross-national survey. Communication Research, 39, 641-661. doi:10.1177/0093650212450584

Preston, P. (2009). Making the news: Journalism and news cultures in Europe. London, England: Routledge.

Reber, B. H., \& Berger, B. K. (2006). Finding influence: Examining the role of influence in public relations practice. Journal of Communication Management, 10, 235-249. doi:10.1108/13632540610681130

Reich, Z. (2010). Measuring the impact of PR on published news in increasingly fragmented news environments. A multifaceted approach. Journalism Studies, 11, 799-816. doi:10.1080/14616701003760550

Reich, Z., \& Hanitzsch, T. (2013). Determinants of journalists' professional autonomy: Individual and national level factors matter more than organizational ones. Mass Communication and Society, 16, 133-156. doi:10.1080/15205436.2012.669002

Riesmeyer, C. (2007). Wie unabhängig ist Journalismus? Zur Konkretisierung der Determinationsthese [How independent is journalism? Toward a specification of the determination thesis]. Konstanz, Germany: UVK.

Ryan, M., \& Martinson, D. L. (1988). Journalists and public relations practitioners: Why the antagonism? Journalism Quarterly, 65, 131-140. doi:10.1177/107769908806500118

Sallot, L. M., \& Johnson, E. A. (2006). Investigating relationships between journalists and public relations practitioners: Working together to set, frame and build the public agenda, 1991-2004. Public Relations Review, 32, 151-159. doi:10.1016/j.pubrev.2006.02.008

Shin, J.-H., \& Cameron, G. T. (2003). The potential of online media: A coorientational analysis of conflict between PR professionals and journalists in South Korea. Journalism \& Mass Communication Quarterly, 3, 583-602. doi:10.1177/107769900308000307 
Shoemaker, P. J., Eichholz, M., Kim, E., \& Wrigley, B. (2001). Individual and routine forces in gatekeeping. Journalism and Mass Communication Quarterly, 78, 233-246. doi:10.1177/107769900107800202

Shoemaker, P. J., \& Reese, S. D. (1996). Mediating the message: Theories of influence on mass media content. White Plains, NY: Longman.

Sigelman, L. (1973). Reporting the news: An organizational analysis. American Journal of Sociology, 79, 132-151. doi:10.1086/225511

Sinaga, S., \& Callison, C. (2008). Credibility of PR practitioners: The impact of professional journalism background on trustworthiness, expertness, and homophily evaluations. Public Relations Review, 34, 291-293. doi:10.1016/j.pubrev.2008.04.002

Sinaga, S. T., \& Wu, H. D. (2007). Predicting Indonesian journalists' use of public relationsgenerated news material. Journal of Public Relations Research, 19, 69-90. doi:10.1080/ 10627260709336596

Soloski, J. (1989). News reporting and professionalism: Some constraints on the reporting of news. Media, Culture \& Society, 11, 207-228. doi:10.1177/016344389011002005

van Dahlen, A., de Vreese, C., \& Albæk, E. (2012). Different roles, different content? A fourcountry comparison of the role conceptions and reporting style of political journalists. Journalism: Theory, Practice and Criticism, 13, 903-922. doi:10.1177/1464884911431538

Waters, R. D., Tindall, N. T. J., \& Morton, T. S. (2010). Media catching and the journalistpublic relations practitioner relationship: How social media are changing the practice of media relations. Journal of Public Relations Research, 22, 241-264. doi:10.1080/10627261003799202

Weaver, D. H. (2015). Studying journalists and journalism across four decades: A sociology of occupations approach. Mass Communication and Society, 18, 4-16. doi:10.1080/15205436. 2014.969843

Weaver, D. H., Beam, R. A., Brownlee, B. J., Voakes, P. S., \& Wilhoit, G. C. (2007). The American journalist in the 21st century: Key findings. Mahwah, NJ: Lawrence Erlbaum.

Weaver, D. H., \& Wilhoit, G. C. (1986). The American journalist: A portrait of U.S. news people and their work. Bloomington: Indiana University Press.

Weaver, D. H., \& Wilhoit, G. C. (1991). The American journalist: A portrait of U.S. news people and their work. Bloomington: Indiana University Press.

Weaver, D. H., \& Wilhoit, G. C. (1996). The American journalist in the 1990s: U.S. news people at the end of an era. Mahwah, NJ: Lawrence Erlbaum.

Weaver, D. H., \& Willnat, L. (2012). The global journalist in the 21st century. New York, NY: Routledge.

Weischenberg, S., Malik, M., \& Scholl, A. (2006). Die Souffleure der Mediengesellschaft: Report über die Journalisten in Deutschland [The prompters of media society: A report on journalists in Germany]. Konstanz, Germany: UVK.

Whitney, D. C., Sumpter, R. S., \& McQuail, D. (2004). News media production: Individuals, organizations, and institutions. In J. Downing, D. McQuail, P. Schlesinger \& E. Wartella (Eds.), The SAGE handbook of media studies (pp. 393-410). Thousand Oaks, CA: SAGE.

Willnat, L., \& Weaver, D. H. (2014). The American journalist in the digital age: Key findings. Bloomington: School of Journalism, Indiana University.

Willnat, L., Weaver, D. H., \& Choi, J. (2013). The global journalist in the twenty-first century. A cross-national study of journalistic competencies. Journalism Practice, 7, 163-183. doi: $10.1080 / 17512786.2012 .753210$ 


\section{Author Biographies}

Magdalena Obermaier is a research associate at the Department of Communication Studies and Media Research, Ludwig-Maximilians-University of Munich, Germany. Her research focuses on media effects, effects of persuasive communication, and the relationship between journalism and public relations. She can be reached at magdalena.obermaier@ifkw.lmu.de.

Thomas Koch is a professor at the Department of Communication Science, Johannes GutenbergUniversity of Mainz, Germany. His research focuses on effects of persuasive communication, the relationship between journalism and public relations, media use, and political communication. He can be reached at thomas.koch@uni-mainz.de.

Claudia Riesmeyer is a research associate at the Department of Communication Studies and Media Research, Ludwig-Maximilians-University of Munich, Germany. Her research focuses on media literacy, journalism and public relations, political communication, and methods. She can be reached at claudia.riesmeyer@ifkw.lmu.de. 